\title{
Amphetamine Redistributes Dopamine from Synaptic Vesicles to the Cytosol and Promotes Reverse Transport
}

\author{
David Sulzer, ${ }^{1,2,4,5}$ Ta-Kung Chen, ${ }^{6}$ Yau Yi Lau, ${ }^{6}$ Helle Kristensen, ${ }^{6}$ Stephen Rayport, ${ }^{1,3,4,5}$ and Andrew Ewing ${ }^{6}$ \\ Departments of 'Psychiatry, ${ }^{2}$ Neurology, and ${ }^{3}$ Anatomy and Cell Biology, and ${ }^{4}$ Center for Neurobiology and \\ Behavior, Columbia University, New York, New York 10032, ${ }^{5}$ Department of Neuroscience, New York State \\ Psychiatric Institute, New York, New York 10032, and ${ }^{6}$ Department of Chemistry, Penn State University, University \\ Park, Pennsylvania 16802
}

\begin{abstract}
Whether amphetamine acts principally at the plasma membrane or at synaptic vesicles is controversial. We find that $d$-amphetamine injection into the Planorbis giant dopamine neuron causes robust dopamine release, demonstrating that specific amphetamine uptake is not required. Arguing for action at vesicles, whole-cell capillary electrophoresis of single Planorbis dopamine neurons shows that amphetamine reduces vesicular dopamine, while amphetamine reduces quantal dopamine release from PC12 cells by $>50 \%$ per vesicle. Intracellular injection of dopamine into the Planorbis dopamine neuron produces rapid nomifensinesensitive release, showing that an increased substrate concentration gradient is sufficient to induce release. These experiments indicate that amphetamine acts at the vesicular level where it redistributes dopamine to the cytosol, promoting reverse transport, and dopamine release.
\end{abstract}

[Key words: amphetamine, reverse transport, synaptic vesicles, PC12 cells, Planorbis corneus, amperometry, electrochemistry]

Amphetamines are dopamine (DA) transporter substrates that induce calcium-independent monoamine release. Exactly how this occurs has been controversial (Seiden et al., 1993). In the exchange diffusion model, the DA transporter is postulated to have a mobile site that mediates the translocation of DA across the membrane. $d$-Amphetamine (AMPH) is thought to act by substituting for DA, driving the carrier to the internal face of the plasma membrane where the site binds cytoplasmic DA and then releases it on returning to the external face (Fischer and Cho, 1979). Although monoamine uptake transporters have been sequenced (Amara and Kuhar, 1993; Giros and Caron, 1993), it is not clear whether their putative structures define a channel or a carrier (Levi and Raiteri, 1993).

In the weak base model (Sulzer and Rayport, 1990; Sulzer et al., 1993), AMPH-like psychostimulants are thought to redis-

Received Nov. 3, 1994; revised Dec. 29, 1994; accepted Jan. 4, 1994

We thank Drs. Qais Al-Awqati, Susan Amara, Robert Edwards, George Uhl, and the late Eric Holtzman for their comments. This work was supported by NIDA Grant DA07418 (D.S.), NIMH MH00705 and MH44736 (S.R.), NIH and ONR (A.G.E.). The Parkinson's Disease Foundation provided support in the final stages of this project (D.S.). S.R. is a Burroughs Wellcome Scholar in Experimental Therapentics and this work was supported in part by a grant from the Burroughs Wellcome Fund. A.G.E. is a Camille and Henry Dreyfus Teacher Scholar.

Correspondence should be addressed to David Sulzer, Ph.D., Black Building 307, Columbia University, 650 West 168th Street, New York, NY 10032.

Copyright $(1995$ Society for Neuroscience $0270-6474 / 95 / 154102-07 \$ 05.00 / 0$ tribute catecholamines from synaptic vesicles to the cytosol by collapsing the vesicular proton gradient that provides the free energy for neurotransmitter accumulation (Ereckinska et al., 1987; Sulzer and Rayport, 1990; Rudnick and Wall, 1992). This would increase the availability of transmitter for reverse transport without requiring a mobile site. In support of this model, weak bases and protonophores, which cause an AMPH-like release of DA from isolated vesicles (Sulzer and Rayport, 1990) but are not substrates for the uptake transporter, induce reverse transport in cultured DA neurons (Sulzer et al., 1993). In addition, low-affinity binding of AMPH to the vesicular transporter (Gonzalez et al., 1993; Schuldiner et al., 1993) may block vesicular uptake and cause a redistribution of DA similar to that mediated by collapse of synaptic vesicle proton gradients.

The inhibition of AMPH action by uptake blockers including cocaine and nomifensine (Fischer and Cho, 1979; Liang and Rutledge, 1982; Hurd and Ungerstedt, 1989) suggests that up take of AMPH as a substrate is required. However, it is not clear whether AMPH uptake alone is sufficient or whether AMPH acts intracellularly to promote DA release. To differentiate between the plasma membrane and synaptic vesicles as the principal site of AMPH action, we have used identified DA neurons to ask whether injections of AMPH, which bypass the uptake transporter, cause DA release. Then to clarify the mode of action, we have used recently developed microelectrochemical techniques to measure AMPH-induced redistribution of DA across the vesicular and plasma membranes. Finally, we have addressed the role of the plasma membrane transporter by monitoring DA release due to intracellular DA injection in real time.

\section{Materials and Methods}

GDC electrochemistry. The use of the Planorbis corneus giant dopamine cell (GDC) for electrochemical experiments has been described previously (Chien et al., 1990; Ewing et al., 1992). Briefly, adult Planorbis corneus were obtained from NASCO (Fort Addison, WI) and dissected to reveal the left pedal ganglion, which was immersed in 10 $\mathrm{ml}$ of snail saline and desheathed to expose the GDC. Snail saline contained $39 \mathrm{~mm} \mathrm{NaCl}, 1.3 \mathrm{mM} \mathrm{KCl}, 4.5 \mathrm{mM} \mathrm{CaCl}_{2}, 1.5 \mathrm{mM} \mathrm{MgCl}_{2}, 6.9$ $\mathrm{mM} \mathrm{NaHCO}, \mathrm{pH} 7.4$. Intracellular injections of $\Lambda \mathrm{MPH}$ or DA were carried out with pulled glass capillaries $(0.5 \mu \mathrm{m}$ tips) and an Eppendorf model 5242 pressure-based microinjector. Injection volumes were calibrated by injection of aqueous solution into mineral oil under microscopic observation and calculation of the volume of the spherical droplet. For AMPH injections, a $2 \mu \mathrm{m}$ carbon ring ultramicroelectrode touching the GDC membrane was held at a steady potential of $0.8 \mathrm{~V}$ and the oxidation current measured over time. For DA injection experiments, the carbon ring electrode was again placed immediately against the GDC. Staircase voltammetry ( -0.2 to $0.8 \mathrm{~V}, 50 \mathrm{steps}, 20 \mathrm{mV} / \mathrm{step}$, $50 \mathrm{msec} / \mathrm{step}$ ) was used throughout to monitor DA release; current was 
sampled from each plotted voltammogram at $0.8 \mathrm{~V}$ versus a sodiumsaturated calomel reference electrode and plotted with respect to time. Nomifensine was applied by bath perfusion. All experiments were conducted at room temperature.

Single cell capillary electrophoresis. To measure the vesicular DA pool, single GDCs from juvenile snails were drawn into $25 \mu \mathrm{m}$ i.d. $\times$ $75 \mathrm{~cm}$ long capillaries (Olefirowicz and Ewing, 1990; Kristensen et al., 1994). A 1 min injection of morpholinoethanesulfonic acid buffer $(\mathrm{pH}$ 5.65) was timed to produce an optimal differential lysis of the plasma but not vesicular membranes. The resulting cellular components were then separated by electrophoretic mobility in a $25 \mathrm{kV}$ field applied to the capillary and detected using a carbon fiber electrode held at $0.8 \mathrm{~V}$.

PC 12 cell quantal analysis. PC12 cells were obtained from the American Type Culture Collection (Rockville, MD) and maintained using established methods (Greene and Tischler, 1976). The catecholamine present in these cultures consists mostly of dopamine (about 90\%); the remainder is mostly norepinephrine (E. Pothos and D. Sulzer, unpublished observations). Recording media contained $150 \mathrm{mM} \mathrm{NaCl}, 4.2 \mathrm{~mm}$ $\mathrm{KCl}, 1.0 \mathrm{~mm} \mathrm{NaH} \mathrm{PO}_{4}, 11.2 \mathrm{~mm}$ glucose, $0.7 \mathrm{~mm} \mathrm{MgCl}, 2 \mathrm{mM} \mathrm{CaCl}$, $10 \mathrm{~mm}$ HEPES (pH 7.4). Amperometric detection of individual exocytic events were monitored with a $5 \mu \mathrm{m}$ diameter carbon fibcr clectrode (Kelly and Wightman, 1986) using an EI-400 potentiostat (Ensman Instrumentation, Bloomington, IN) and recorded to disk (Gateway 2000 PC) with a LabMaster Interface (Scientific Solutions, Solon, $\mathrm{OH}$ ). The working electrode was placed on a target cell and gently pushed down against the cell body (about $1 \mu \mathrm{m}$ ) with a piezo-micropositioner (PCS750/1000, Burleigh Instruments, Fishers, NY). Micropipettes containing stimulants were placed $10 \mu \mathrm{m}$ above the substrate and $150 \mu \mathrm{m}$ away from the target cell by micropositioners (Mertzhauser, Germany). Chemical stimulants were delivered by $6 \mathrm{sec}$ pressure pulses from a microinjector (Picospritzer II, General Valve, Fairfield, NJ). The estimated total injection volume was $30 \mathrm{nl}$ per injection. Stimulation was carried out with a mixture of $105 \mathrm{mM} \mathrm{KCl}$ and $1 \mathrm{~mm}$ nicotine, as this was found to produce more exocytic events than elevated potassium or 1 mm nicotine applied separately.

The output from the potentiostat was digitized at $820 \mathrm{~Hz}$ and analyzed using a locally written program (Chen et al., 1994). In short, a noise threshold was set as a slope of 1.4 times the average slope of the $60 \mathrm{~Hz}$ noise ( 18 consecutive $60 \mathrm{~Hz}$ peaks). Peaks were defined as beginning at the starting point of any four consecutive data points, with positive slopes greater than the noise threshold. The ends of the peaks were defined as either the first point of four consecutive data points with a positive slope immediately after a negative slope or the value of the starting point of the peak, whichever was higher. Only peaks with baseline width between 9 and $29 \mathrm{msec}$ (about $99 \%$ of the peaks identified) were considered in order to eliminate very rapid current transients or rare wide peaks that could represent overlapping multiple events. The number of molecules oxidized at the electrode face was determined by the relation $N=Q / \mathrm{n} \mathcal{F}$, wherc $Q$ is the charge of the peak, $n$ was assumed to be 2 (for catecholamines), $N$ is the number of moles and $\mathcal{F}$ is Faraday's constant $(96,485$ coulombs per equivalent).

\section{Results}

Intracellular AMPH injection and $D A$ release

The left pedal ganglion of the pond snail Planorbis corneus contains a single giant DA neuron (GDC) that closely resembles mammalian DA neurons in several ways (Osborne et al., 1975). The GDC displays nomifensine-sensitive DA uptake, reserpinesensitive vesicular DA uptake, and metabolizes DA to dihydroxyphenylacetic acid (DOPAC). However, unlike mammalian DA neurons, the adult GDC is approximately $200 \mu \mathrm{m}$ in diameter, facilitating single cell analysis; and, it lacks ascorbic acid (Barber and Kempter, 1986), facilitating the unambiguous electrochemical detection of DA.

We measured DA release in real time with carbon fiber microelectrodes (Wightman et al., 1991) touching the extracellular face of the GDC membrane (Fig. 1A). Injection of 8 pl of 100 $\mathrm{mM}$ d-AMPH into the GDC rapidly released DA (Fig. $1 B$ ). Based on an estimated cytosolic volume of $8 \mathrm{nl}$, the injection resulted in an intracellular concentration of about $100 \mu \mathrm{M}$ AMPH. Although AMPH is amphiphilic and may diffuse from
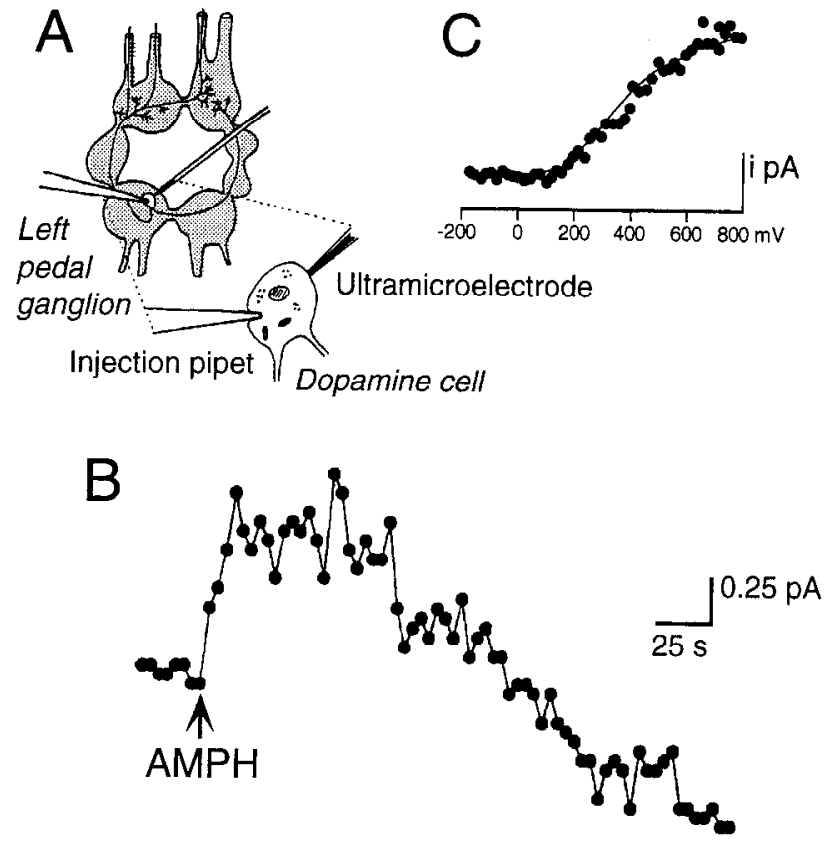

Figure 1. Intracellular injection of AMPH promotes DA release. A, Single GDCs from adult Planorbis corneus were impaled with an AMPH containing pipette. Oxidation current was measured with a 2 $\mu \mathrm{m}$ carbon ring ultramicroelectrode touching the GDC membrane and held at a steady potential of $0.8 \mathrm{~V}$. B, AMPH ( $8 \mathrm{pl}$ of $100 \mathrm{mM}$ ) was injected intracellularly (arrow), thereby bypassing the uptake transporter, and the increase in extracellular DA measured. Similar levels of DA release were found in three replications of the experiment using DC amperometry. The small, slow baseline decrease during these experiments results from adsorption of electrode oxidation products to the electrode surface (Lau et al., 1991). C, The shape of the voltammogram ( -0.2 initial potential to $0.8 \mathrm{~V}$ final potential) taken at the peak current value $14 \mathrm{sec}$ postinjection (filled circles) closely matched the voltammogram for a DA standard (solid line). AMPH, which lacks hydroxyl groups, is not oxidized at these potentials. Calibration: $i=0.5$ for the experiment and 31.5 for the standard.

the cell, it also diffuses rapidly in aqueous medium and would reach nanomolar levels within milliseconds. Extracellular DA increased following the injection, reaching a maximum of 1.43 $\pm 0.58 \mu \mathrm{M}$ (mean $\pm \mathrm{SEM}, n=3$ ). The shape of a voltammogram taken at the peak current value closely matched the voltammogram of a DA standard (Fig. 1C).

\section{Measurement of the vesicular DA pool}

To cxamine the effects of AMPH on the vesicular pool directly, we measured vesicular DA by capillary electrophoresis of juvenile GDCs (75 $\mu \mathrm{m}$ in diameter) (Kristensen et al., 1994). Time-limited membrane lysis of single GDCs produces two distinct DA peaks (Fig. 2, lower trace; cf. Kristensen et al., 1994). Peak 1 is narrow and appears at the same time as a DA standard, indicating that it reflects free DA and DA from a readily releasable vesicular pool. Peak 2 appears later and is broader; furthermore, it is abolished by prior reserpine treatment or by more extensive lysis, indicating that it reflects a slower release of DA during electrophoresis from vesicles that have not undergone exocytosis. Thus, peak 2 provides a measure of vesicular DA principally in storage vesicles.

We found that prior treatment with AMPH (10 $\mu \mathrm{M}$ for 15 min) reduced peak 2 to below detectable limits and correspondingly increased peak 1 (Fig. 2, upper trace; Table 1). 


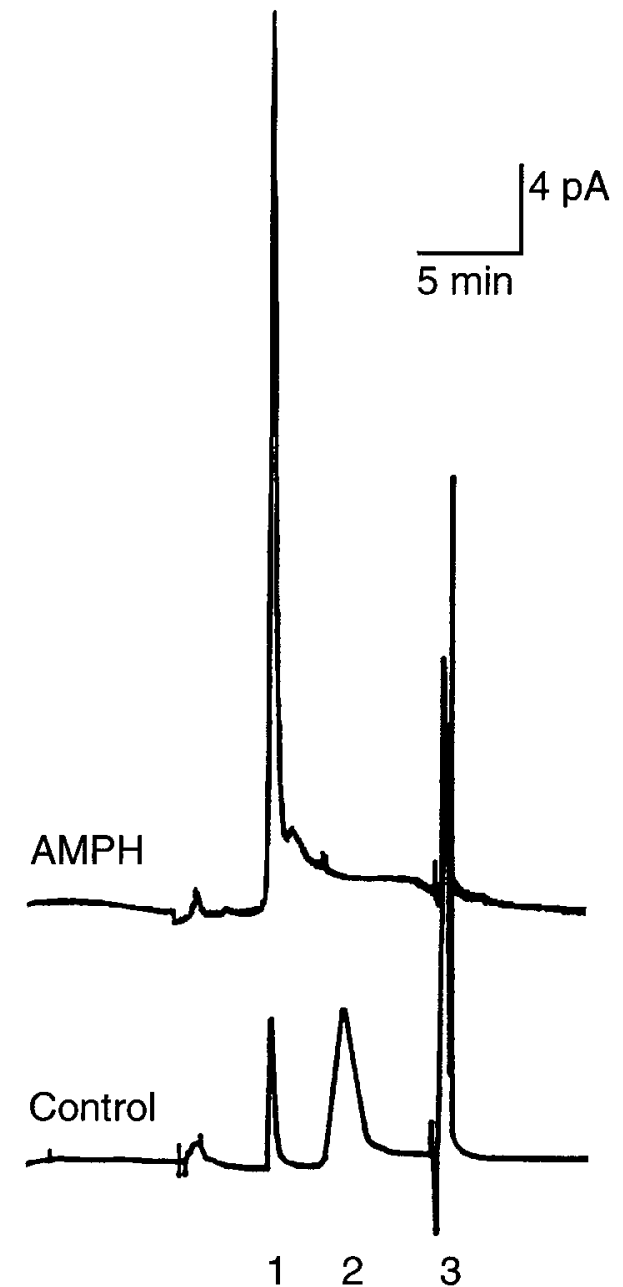

Figure 2. Electrophoretic separation of readily oxidized components from a single Planorbis corneus giant DA neuron. Single neurons (75 $\mu \mathrm{m}$ diameter) from juvenile snails were drawn into capillary tubes. Subsequent injection of morpholinoethanesulfonic acid buffer ( $\mathrm{pH} 5.65$ ) for 1 min produced a partial lysis of the cell membranes, presumably mainly the plasma membrane. Based on this differential lysis, peak 1 reflects free $D \Lambda$ and $D \Lambda$ from easily released vesicles and peak 2 re flects vesicular DA (see text); peak 3 reflects other oxidizable compounds with a net neutral charge (Kristensen et al., 1994). AMPH treatInent increased peak 1 and reduced peak 2 to undetectable levels (see Table 1).

\section{AMPH modulation of quantal size}

To measure changes in the DA content of individual secretory vesicles, we monitored individual catecholamine release events (Wightman et al., 1991) in undifferentiated PC12 cells (Chen et al., 1994), where release occurs from the cell body. Quantal packets were measured with a detection limit of 19,000 molecules. Since spontaneous release events in PC12 cells were rarely observed and undifferentiated PC12 cells do not produce action potentials, the cells were stimulated by local perfusion with nicotine and $\mathrm{KCl}$ (Chen et al., 1994). In each case, release events were measured for approximately $2 \mathrm{~min}$ following stimulation. In controls, individual exocytic events corresponded to the release of $111,000 \pm 32,000$ catecholamine molecules $(n=9$ cells, $92 \pm 37$ events per cell, mean \pm SEM). AMPH $(10 \mu \mathrm{M}$ for $10 \mathrm{~min}$ ) reduced stimulated catecholamine released per exocytic event. Randomly chosen amperograms for exocytosis from control cells and those treated with AMPH are shown in
Table 1. Reduction of vesicular DA by amphetamine in an identified neuron

\begin{tabular}{lll} 
& Control & AMPH \\
\hline Peak 1 & $6.1 \pm 3.0$ & $107 \pm 23$ \\
Peak 2 & $19 \pm 9.1$ & $<0.01$
\end{tabular}

Data are mean \pm SEM $(n=3)$ for DA (fmol) peaks in single GDCs from juvenile Planorbis corneus measured by capillary electrophoresis. Cells were exposed to $10 \mu \mathrm{M}$ AMPH for 15 min prior to sampling. The detection limit is typically $1-10$ amol.

Figure 3, $A$ and $B$. When paired with age-matched controls from sister cultures $(n=3,139 \pm 105$ events per cell), the average exocytic event following incubation with AMPH $(n=7$ cells, $34 \pm 9$ events per cell) decreased to $48 \pm 5.4 \%$ of control (Fig. $3 C$ ); very few vesicles releasing $>200,000$ molecules were present following AMPH.

\section{$D A$ release due to intracellular DA injection}

To determine whether increased cytosolic DA is sufficient to induce release, we returned to the GDC. In the resting state, cytosolic DA is about $2.2 \mu \mathrm{M}$ and extracellular DA below the limits of detection (Ewing et al., 1992). Intracellular injection of $4 \mathrm{pl}$ of $0.5 \mathrm{~mm}$ DA (Fig. $4 A$ ) rapidly increased extracellular DA to $22.5 \pm 0.9 \mu \mathrm{M}, 3.5 \mathrm{sec}$ postinjection ( $n=3$ cells); extracellular perfusion with nomifensine (a specific blocker of the DA uptake transporter that, unlike other commonly used uptake blockers, has no detectable effect on intracellular proton gradients; Sulzer et al., 1993) attenuated the increase in extracellular DA following subsequent injections by $87 \pm 4 \%$. After removal of nomifensine, the increase in extracellular DA due to intracellular DA injection returned to near control levels $(20.4 \pm 1.5$ $\mu \mathrm{M}$ pcak concentration, $p=0.265$ by Student's $t$ test, not significantly different). Intracellular injections of control solution lacking DA induced no DA release (data not shown). Difference voltammograms taken after the first, second, and fourth DA injections (Fig. 4B) closely resembled voltammograms of DA obtained by in vitro calibration.

\section{Discussion}

Whether AMPH acts principally at the plasma membrane uptake transporter or at the vesicular level has been controversial. We used two model systems to address this issue. Arguing for a principal mechanism of action at the vesicular level, intracellular injection of AMPH into the Planorbis GDC, which bypasses the plasma membrane uptake transporter, causes DA release. Wholecell capillary electrophoresis of GDCs shows that AMPH profoundly reduces vesicular DA; and amperometric detection of $\mathrm{DA}$ release in $\mathrm{PC} 12$ cells shows that $\triangle \mathrm{MPH}$ significantly reduces DA release from individual exocytic events. Taken together, these results indicate that amphetamine redistributes DA from synaptic vesicles to the cytosol. Monitoring DA at the extracellular face of the GDC plasma membrane shows that intracellular injection of DA produces rapid nomifensine-sensitive release, indicating that increased cytosolic DA is sufficient to trigger reverse transport.

\section{AMPH acts intracellularly}

Injection of AMPH directly into the cytosol of the GDC causes DA release even though the uptake transporter is bypassed and the AMPH concentration gradient is in the opposite direction from that required for net efflux via exchange diffusion. Togeth- 

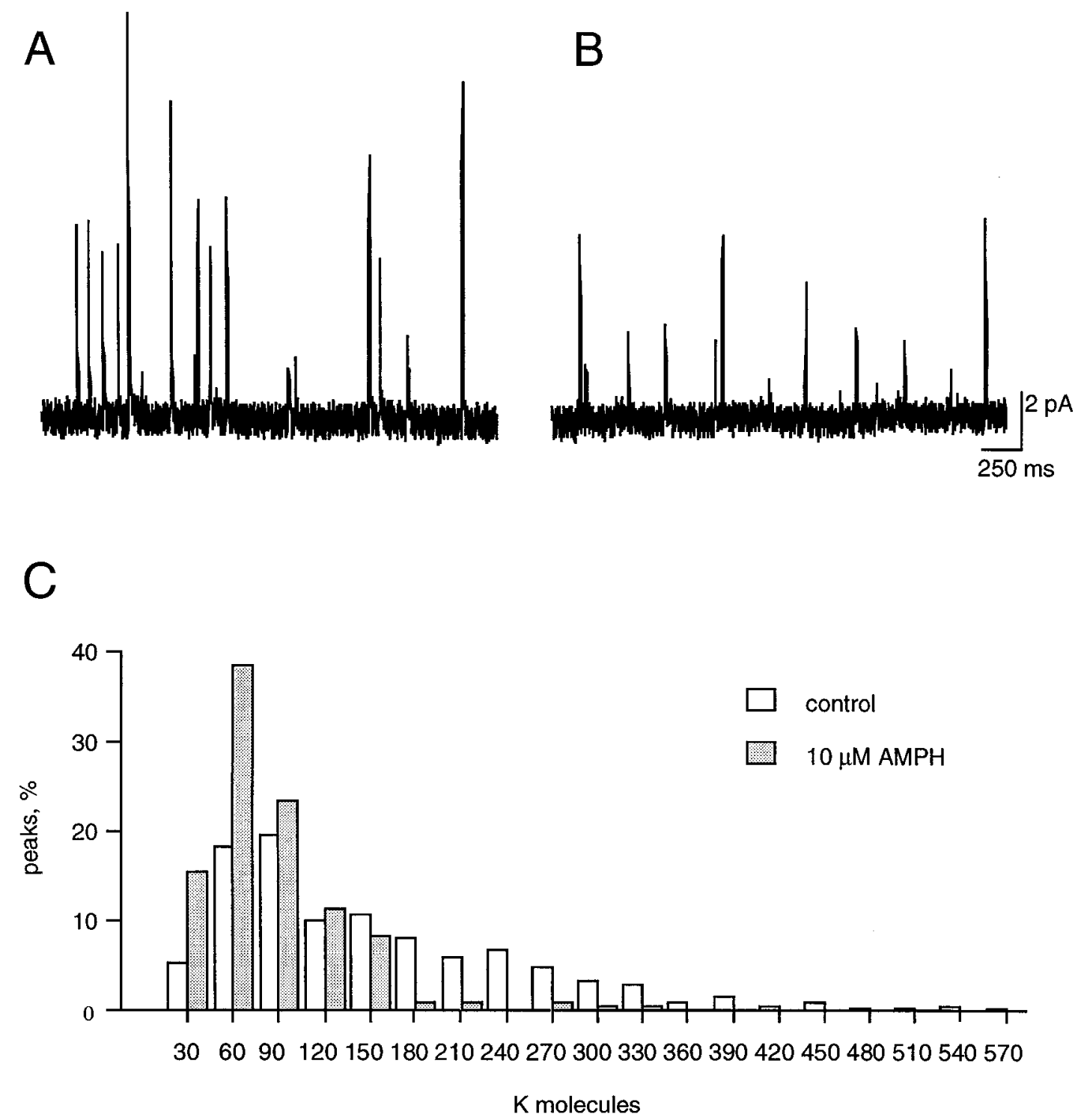

Figure 3. AMPH exposure decreases the quantal amplitude of individual release events from PC12 cells. Randomly chosen electrochemical records of quantal release for $(A)$ a control cell and $(B)$ a cell that has been incubated in $10 \mu \mathrm{M} d$-AMPH for 10 min. Cells were stimulated by local perfusion $(30 \mathrm{nl}$ of $1 \mathrm{mM}$ nicotine in $105 \mathrm{mM} \mathrm{KCl}$ saline) to induce vesicular exocytosis. $C$, A histogram shows the percentage of peak sizes in paired control and AMPH-treated cells. Peaks are combined in intervals of 30,000 molecules. The lower limit of each bin size is shown on the abscissa.

er with the uptake of AMPH by catecholamine transporters (Zaczek et al., 1991), which would play a role in the specificity of transmitter release, and the ability of AMPH to release monoamines from isolated vesicles (Slotkin and Kirshner, 1971; Knepper et al., 1988; Sulzer and Rayport, 1990), these observations argue for an intracellular site of AMPH action.

Consistent with redistribution of DA from vesicles to cytosol, capillary electrophoresis of single GDCs shows that AMPH redistributes DA from the putative vesicular DA pool. The redistribution of DA is greater than that from isolated vesicles (Sulzer and Rayport, 1990), perhaps because intracellular AMPH concentrations are increased due to specific uptake (Zaczek et al., 1991). Moreover, the magnitude of the increase in free DA apparently exceeds the reduction in the vesicular peak. This could result either from blockade of DA metabolism due to AMPHmediated monoamine oxidase inhibition or from elevated DA synthesis. Alternatively, the disproportionate increase in free DA could be due to lysis of vesicles, leading to an underestimate of the vesicular pool and an overestimate of free DA. Nonetheless, the intact vesicular peak provides a measure of the major fraction of vesicular DA, and its profound reduction by AMPH favors an action of AMPH at the vesicular level. A number of reports on the effects of reserpine on AMPH-induced release (Parker and Cubeddu, 1986; Seiden et al., 1993; St. Remy et al., 1994) have been used to argue for and against models requiring AMPH action at the vesicular level. The present capillary electrophoresis results support a role for a vesicular pool in AMPHinduced DA release.

Furthermore, monitoring individual exocytic release events in undifferentiated $\mathrm{PC} 12$ cells, where vesicular release from the cell body can be measured, shows that AMPH reduces the transmitter content of individual vesicles. This occurs with $10 \mu \mathrm{M}$ AMPH, a level reached in the brain with a standard dose $(1 \mathrm{mg} /$ $\mathrm{kg}$ ) (Melega et al., 1992), and shows for the first time a reduction 

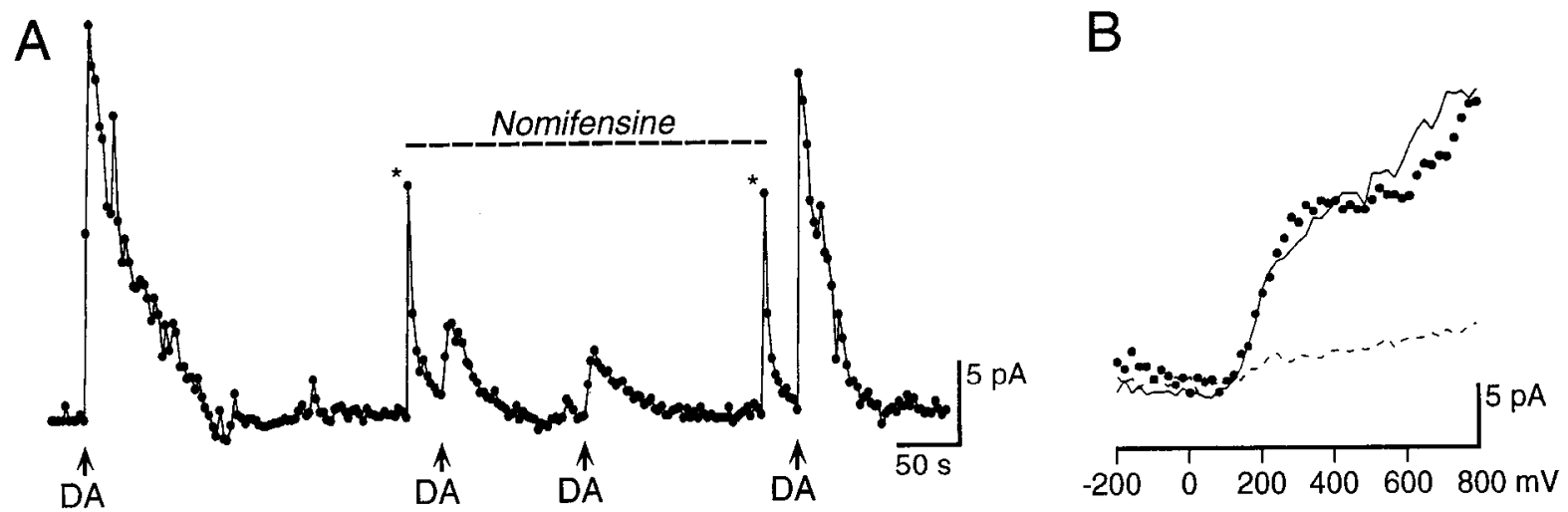

Figure 4. Intracellular injection of DA induces reverse transport. A, Intracellular injection of $4 \mathrm{pl}$ of $0.5 \mathrm{mM}$ DA (arrows) reliably increases extracellular DA. During extracellular perfusion with $10 \mu \mathrm{M}$ nomifensine (dashed line), the DA release due to the same DA injections was markedly attenuated. Perfusion with nomifensine-containing medium and its replacement by control medium produce current spikes (asterisks). These data have becn baseline corrected by subtracting a curve fitted to the background signal. $B$, Background subtracted voltammograms (from -0.2 to 0.8 $\mathrm{V})$ for the first (O), second (dashed line) and fourth (solid line) intracellular DA injections shown in $A$. The voltammograms monitored at the face of the neuron are similar to DA. Although the shapes of the voltammograms differ slightly at potentials above $0.5 \mathrm{~V}$, all three voltammograms are sigmoidal with a half-wave potential of approximately $0.2 \mathrm{~V}$.

in quantal size (greater than 50\%) due to a self-administered drug. In conjunction with the well-established role of AMPH in promoting stimulation independent catecholamine release, these findings demonstrate that AMPH can attenuate stimulus-dependent release by reducing quantal size. These experiments do not, however, differentiate between collapse of the proton gradient (Sulzer and Rayport, 1990) and blockade of the vesicular amine transporter (Reith et al., 1993; Schuldiner et al., 1993), which binds AMPH with low-affinity (Gonzalez et al., 1994), and it may be that both effects play roles. Taken together, these experiments argue that AMPH principally redistributes DA from synaptic vesicles to the cytosol.

Alterations of the DA packaged in individual vesicles would be expected to profoundly affect synaptic transmission. Quantal analysis studies generally assume that the packaging of neurotransmitter per synaptic vesicle is invariant (Redman, 1990). However, the present evidence, in conjunction with prior electrochemical results showing considerable variability in the size of release events (Wightman et al., 1991; Chow et al., 1992), suggests that alterations of quantal size could play an important role in the modulation of neurotransmitter release.

\section{Elevated cytosolic DA induces reverse transport}

Injection of DA into the cytosol of GDCs leads to a rapid release of DA that is nomifensine sensitive. Uptake transport blockers like nomifensine are thought to block transport by binding to the extracellular face of the DA transporter; however, unlike AMPH, they are not transported (Anderson et al., 1989; Ritz et al., 1990). We have previously shown in DA neuron cultures that nomifensine blocks DA release induced by AMPH, weak bases, and protonophores (Sulzer et al., 1993), arguing that nomifensine blocks DA reverse transport. Since in the present experiments nomifensine blocks substrate flux across the DA transporter, most DA release following intracellular injection occurs via reverse transport.

While intracellular injections of DA produce maximal extracellular levels within $3.5 \mathrm{sec}$, AMPH injection induces maximal DA release more slowly (compare Figs. $1 B, 4 A$ ). This slower action of AMPH would be consistent with a rate-limiting step of AMPH-mediated redistribution of DA from synaptic vesicles to the cytosol. Altered substrate plasma membrane concentration gradients due to vesicular AMPH sequestration could further affect DA flux across the transporter. The extent to which AMPH increases cytosolic D $\Lambda$ will depend, in part, on the kinetics of reverse transport; since reverse transport due to DA is more rapid, increased AMPH-induced cytosolic DA levels are likely to be short lived.

The present experiments show transporter-mediated release from neurons in real time. This release can be induced solely by an increased transmitter concentration gradient without alteration of transmembrane ionic gradients. The release reaches physiologically significant levels since the extracellular DA measured in these experiments greatly exceeds the binding constants of DA receptors (O'Dowd et al., 1994). Previously, reverse transport from retinal neurons was demonstrated using GABA uptake blocker-dependent currents in postsynaptic neurons (Schwartz, 1987) and in glial cells using voltage clamp techniques modeled to represent uptake-dependent potassium flux (Szatkowski et al., 1990). More generally, reverse transport appears to be an important alternate form of neurotransmitter release (Levi and Raiteri, 1993). Not only do uptake blockers attenuate calcium-independent release of radiolabeled monoamines (Lonart and Zigmond, 1991; McKenna et al., 1991), but they also attenuate release of GABA (Haycock et al., 1978; Pin and Bockaert, 1989; Bernath and Zigmond, 1990; Dunlop et al., 1991; O’Malley et al., 1992; Hitri et al., 1994), and glutamate or aspartate (Dunlop et al., 1992; Turner et al., 1992). Reverse transport of GABA appears to mediate signaling between retinal horizontal and cone cells (Schwart7, 1987), reverse transport of glycine appears to modulate hippocampal NMDA receptors (Adam-Vizi, 1992; Attwell et al., 1993), and reverse transport of glutamate during ischemia appears to be an important mode of release (Adam-Vizi, 1992; Attwell et al., 1993). Our results now add a role for reverse transport in AMPH-induced DA release.

\section{Conclusions}

These findings demonstrate in invertebrate DA neurons and PC1 2 cells that AMPH decreases vesicular DA content, presumably resulting in DA redistribution to the cytosol. Cytosolic DA is, in turn, rapidly released by reverse transport. Since AMPHinduced DA release occurs independently of specific AMPH up- 
take by the plasma membrane transporter and can be induced in isolated monoamine vesicles (Slotkin and Kirshner, 1971; Knepper et al., 1988; Sulzer and Rayport, 1990), the present findings favor the release of DA from the vesicular pool.

This mechanism has important implications for neurotransmission and pathology. It suggests that AMPH affects synaptic transmission both by increasing activity-independent reverse transport and by decreasing the amount of transmitter released during activity-dependent vesicular exocytosis. The result should be a reduction in the signal-to-noise ratio of stimulation-dependent monoamine synaptic transmission. Furthermore, this redistribution of DA from the relatively reducing environment of the synaptic vesicle to the cytosol appears to cause local increases in intracellular oxidative stress in DA neuron axons (Cubells et al., 1994) that may initiate AMPII neurotoxicity.

\section{References}

Adam-Vizi V (1992) External $\mathrm{Ca}^{2+}$-independent release of neurotransmitters. J Neurochem 58:395-405.

$\Lambda$ mara SG, Kuhar MJ (1993) Neurotransmitter transporters: recent progress. Annu Rev Neurosci 16:73-93.

Andersen PH (1989) The dopamine uptake inhibitor GBR 1209: selectivity and molecular mechanism of action. Eur J Pharmacol 166: 493-504.

Attwell D, Barbour B, Szatkowski M (1993) Nonvesicular release of neurotransmitter. Neuron 1 1:401-407.

Barber A, Kempter B (1986) Release of endogenous dopamine from nervous tissue of the pond snail Planorbis corneus: a study using high performance liquid chromatography with electrochemical detection. Comp Biochem Physiol 84C:171.

Bernath S, 7igmond M.J (1990) Calcium-independent GABA release from striatal slices: the role of calcium channels. Neuroscience 36 : $677-682$.

Chen TK, Luo G, Ewing AG (1994) Amperometric monitoring of stim ulated catecholamine release from rat pheochromocytoma (PC12) cells at the zeptomole level. Anal Chem 66:3031-3035.

Chien JB, Wallingford RA, Ewing AG (1990) Estimation of free dopamine in the cytoplasm of the giant dopamine cell of Planorbis corneus by voltammetry and capillary electrophoresis. J Neurochem 54:633-638.

Cubells JF, Rayport S, Rajendran G, Sulzer D (1994) Methamphetamine neurotoxicity involves vacuolation of endocytic organelles and dopamine-dependent intracellular oxidative stress. J Neurosci 14: $2260-2271$.

Dunlop J, Grieve A, Schousboe A, Griffiths R (1991) Stimulation of gamma- ${ }^{3}[\mathrm{H}]$ aminobutyric acid release from cultured mouse cerebral cortex neurons by sulphur-containing excitatory amino acid transmitter candidates: receptor activation mediates two distinct mechanisms of release. J Neurochem 57:1388-1397.

Dunlop J, Grieve A, Darngaard I, Schousboe A, Griffiths R (1992) Sulphur-containing excitatory anino acid-evoked $\mathrm{Ca}^{2+}$-independent release of $d-^{3}[\mathrm{H}]$ aspartate from cultured cerebellar granule cells: the role of glutamate receptor activation coupled to reversal of the acidic amino acid plasma membrane carrier. Neuroscience 50:107-115.

Ereckinska M, Pastuszko A, Wilson DF, Nelson D (1987) Ammoniainduced release of neurotransmitters from rat brain synaptosomes: differences between the effects on amines and amino acids. J Neurochem 49:1258-1265.

Fwing AG, Stein TS, Iau YY (1992) Analytical chemistry in microenvironments: single nerve cells. Accts Chem Res 25:440-447.

Fischer JF, Cho AK (1979) Chemical release of dopamine from striatal homogenates: evidence for an exchange diffusion model. J Pharmacol Exp Ther 208:203-209.

Giros B, Caron MG (1993) Molecular characterization of the dopamine transporter. Trends Pharmacol Sci 14:43-49.

Gonzalez AM, Walther D, Pazos A, Uhl GR (1994) Synaptic vesicular monoamine transporter expression: distribution and pharmacologic profile. Mol Brain Res 22:219-226.

Greene LA, Tischler AS (1976) Establishment of a noradrenergic clonal line of rat adrenal pheochromocytoma cells which respond to nerve growth factor. Proc Natl Acad Sci USA 73:2424-2498.

Haycock JW, Levy WB, Denner LA, Cotman CW (1978) Effects of elevated $\left[\mathrm{K}^{+}\right]$on the release of neurotransmitters from cortical synaptosomes: efflux or secretion? J Neurochem 30:1113-1125.

Hitri A, Hurd YL, Wyatt RJ, Deutsch SI (1994) Molecular, functional and binchemical characteristics of the dopamine transporter: regional differences and clinical relevance. Clin Neuropharmacol 17:1-22.

Knepper SM, Grunewald GL, Rutledge CO (1988) Inhibition of norepinephrine transport into synaptic vesicles by amphctaminc analogs. J Pharmacol Exp Ther 247:484-494.

Kristensen HK, Lau YY, Ewing AG (1994) Capillary electrophoresis of single cells: observation of two compartments of neurotransmitter vesicles. J Neurosci Methods 51:183-188.

Lau Y, Chien J B, Wong D K Y, Ewing AG (1991) Characterization of the voltammetric response at intracellular carbon ring electrodes. Electroanalysis 3:87-95.

Leitz FH. Stefano FJE (1971) The effect of tyramine, amphetamine, and metaraminol on the metabolic disposition of ${ }^{3} \mathrm{H}$-norepinephrine released from the andrenergic neuron. J Pharmacol Exp Ther 178: $464-473$.

Levi G, Raiteri M (1993) Carrier-mediated release of neurotransmitters. Trends Neurosci 16:415-419.

Lonart G, Zigniond MJ (1991) High glutamate concentrations evoke $\mathrm{Ca}^{2+}$-independent dopamine release from striatal slices: a possible role of reverse dopamine transport. J Pharmacol Exp Ther 256:11321138.

McKenna DJ, Guan XM, Shulgin AT (1991) 3,4-Methylenedioxyamphetamine (MDA) analogues exhibit differential effects on synaptosomal release of ${ }^{3} \mathrm{H}$-dopamine and ${ }^{3} \mathrm{H}-5$-hydroxytryptamine. Pharmacol Biochem Behav 38:505-512.

Melega WP, Williams AE, Scmitz D, Stefano ED, Cho AK (1992) Pharmacokinetic/pharmacodynamic analysis of $d$-amphetamine and $d$-methamphetamine. Soc Neurosci Abstr 18:363.

O'Dowd BI; Seeman P, George SR (1994) Dopamine receptors. In: Handbook of receptors and channels (Peroutka SJ, ed), pp 95-124. Boca Raton, FL: CRC.

Olefirowicz TM, Ewing AG (1990) Dopamine concentration in the cytoplasmic compartment of single neurons determined by capillary electrophoresis. J Neurosci Methods 34:11-15.

O'Malley DM, Sandell JH, Masland RH (1992) Co-release of acetylcholine and GABA by the starburst amacrine cells. J Neurosci 12: 1394-1408.

Parker EM, Cubeddu LX (1986) Effects of $d$-amphetamine and dopamine synthesis inhibitors on dopamine and acetylcholine neurotransmission in the striatum. J Pharmacol Exp Ther 237:179-203.

Pin JP, Bockaert J (1989) Two distinct mechanisms, differentially affected by excitatory amino acids, trigger GABA release from fetal mouse striatal neurons in primary culture. J Neurosci 9:648-656.

Redman S (1990) Quantal analysis of synaptic potentials in neurons of the central nervous system. Physiol Rev 70:165-198.

Reith MEA, Coffey LL, Jobe PC (1993) Structure-activity relationships of cocaine congeners in inhibiting $\left[{ }^{3} \mathrm{H}\right]$ dopamine uptake into brain synaptic vesicles. Soc Neurosci Abstr 19:1849.

Ritz MC, Boja JW, Grigoriadis D, Zaczek R, Carroll FI, Lewis AH, Kuhar MJ (1990) [ $\left.{ }^{3} \mathrm{H}\right]$ WIN 35,065-2: a ligand for cocaine receptors in striatum. $J$ Neurochem 55:1556-1562.

Rudnick G, Wall SC (1992) The molecular mechanism of "ecstasy" [3,4-methylenedioxymethamphetamine (MDMA)]: serotonin transporters are targets for MDMA-induced serotonin release. Proc Natl Acad Sci USA 89:1817-1821.

Schuldiner S, Steiner-Mordoch S, Yelin R, Wall SC, Rudnick G (1993) Amphetamine derivatives interact with both plasma membrane and secretory vesicle biogenic amine transporters. Mol Pharmacol 44: $1227-1231$.

Schwartz EA (1987) Depolarization without calcium can release gamma-aminobutyric acid from a retinal neuron. Science 238:350-355.

Seiden LS, Sabol KE, Ricaurte GA (1993) Amphetamine: effects on catecholamine systems and behavior. Brain Res Bull 31:305-310

Slotkin TA, Kirshner N (1971) Uptake, storage, and distribution of amines in bovine adrenal medullary vesicles. Mol Pharmacol 7:581592.

St. Remy C, Rayport S, Sulzer D (1994) Reserpine abolishes amphetamine-induced dopamine release in ventral midbrain neuronal culture. Soc Neurosci Abstr 20:1622.

Sulzer D, Rayport S (1990) Amphetamine and other psychostimulants reduce $\mathrm{pH}$ gradients in midbrain dopaminergic neurons and chromaffin granules: a mechanism of action. Neuron 5:797-808. 
Sulzer D, Maidment NT, Rayport S (1993) Amphetamine and other weak bases act to promote reverse transport of dopamine in ventral midbrain neurons. J Neurochem 60:527-535.

Szatkowski M, Barbour B, Attwell D (1990) Non-vesicular release of glutamate from glial cells by reversed electrogenic glutamate uptake. Nature 348:443-446.

Turner TJ, Adams ME, Dunlap K (1992) Calcium channels coupled to glutamate release identified by omega-Aga-IVA. Science 258:310 313.

Wightman RM, Jankowski JA, Kennedy RT, Kawagoe KT, Schroeder
TJ, Leszczyszyn DJ, Near JA, Diliberto EJ Jr, Viveros OH (1991) Temporally resolved catecholamine spikes correspond to single vesicle release from individual chromaffin cells. Proc Natl Acad Sci USA 88:10754-10758.

Zaczek R, Culp S, De Souza EB (1991) Interactions of [ $\left.{ }^{3} \mathrm{H}\right] \mathrm{ampheta-}$ mine with rat brain synaptosomes. II. Active transport. J Pharmacol Exp Ther 257:830-835.

Zhou R, Luo G, Ewing, AG (1994) Direct observation of the effect of autoreceptors on stimulated release of catecholamines from adrenal cells. J Neurosci 14:2402-2407. 